\title{
高 Genetically modified mush
}

t is not often that field peas capture national headlines. But that is exactly what occurred late in November when researchers at Australia's Commonwealth Scientific and Industrial Research Organization (CSIRO) published a paper describing changes in the structure and immunogenicity of a common bean protein after transgenic expression in peas. Contrary to media reports, the paper did not provide definitive evidence that the transgenic protein was allergenic in humans. Nor were the changes in protein structure particularly shocking or surprising. What was shocking, however, was the political fallout following the study's announcement.

The field pea is big business in Australia. Each year, the annual harvest brings in around AU\$120 (\$88) million. Infestations of the pea weevil (Bruchus pisorum) remain a problem, however, reducing pea yield, compromising product quality and causing significant economic losses. In the early 1990s, the high economic and environmental costs of controlling weevils by chemical pesticides prompted T.J. Higgins of CSIRO and Maarten Chrispeels of the University of California, San Diego, to collaborate on a project to create a transgenic pea (Pisum sativum) that produces $\alpha$-amylase inhibitor 1 , a protein with insecticidal properties originally isolated from the common bean (Phaseolus vulgaris) that is normally absent in peas.

This protein inhibitor works by suppressing the activity of pea weevil $\alpha$-amylase, an enzyme required by the insect to digest starch in pea cotyledons. Weevils that feed on peas expressing the inhibitor essentially starve to death. In six field trials between 1996 and 2001, peas expressing amylase inhibitor not only achieved yields comparable to nontransgenic peas but also demonstrated a remarkable (99.5\%) level of resistance to weevils.

Against this promising background and as part of its risk assessment, the CSIRO team sought to establish whether there were any differences in immune responses elicited in BALB/c mice exposed to the pea form of the $\alpha$-amylase inhibitor or the native form in beans. Unlike mice fed on a diet of wild-type peas (lacking the $\alpha$-amylase inhibitor) or bean (containing the native inhibitor), animals that had previously ingested transgenic peas exhibited elevated levels of antigen-specific IgG1 in serum, enhanced delayed-type hypersensitivity responses in skin and increased reactivity to other food antigens.

The results convincingly demonstrate that oral ingestion of the transgenic amylase inhibitor in peas induces a $\mathrm{CD} 4^{+}$T-helper cell type 2 (Th2) inflammatory response in mice that is absent in animals fed on beans. Altered antigenicity correlates with differences in glycosylation and/or other post-translational modifications at the same residues within the inhibitor. On the basis of these data, CSIRO discontinued the program.

That is about as much as can be said. Although Th2 responses are commonly associated with allergic responses, the failure to measure antigen-specific IgE (the immunoglobulin indicative of allergy) precludes a definitive conclusion. We do not know whether immunogenicity equates to allergenicity. We do not know whether BALB/c mice immune responses are analogous to allergic responses in humans. And we do not know whether the concentration of amylase inhibitor in peas ( $4 \%$ of total protein) was similar to that in beans. This last point is important as the abundance of a protein can strongly influence its allergenicity.

Although $\alpha$-amylase inhibitors from legumes are not known to cause allergies, those found in cereals belong to the prolamine superfamily of proteins that is well represented in lists of known allergens. Many of these are small, sulfur-rich seed proteins that also include the $2 \mathrm{~S}$ albumin protein from Brazil nuts (Bertholletia excelsa). If $2 S$ albumin sounds familiar, that is because soybeans expressing the very same protein remain the only documented example of a transgenic crop discontinued because of evidence of a risk of allergenicity.

The key question is whether the transgenic pea protein would have been flagged by current internationally recognized Codex Alimentarius Commission (CODEX) food standards. The answer appears to be yes. Such assessments are based on sequence homology to known allergens or serum IgE screening with sera from patients allergic to the source of the gene (or sources showing significant homology). A search of a database of known allergens (http://www.allergenonline.com/) reveals limited amino acid sequence identity ( $\sim 35-39 \%)$ between the $P$. vulgaris $\alpha$-amylase inhibitor and minor allergens of peanut and soybean. As the inhibitor is resistant to pepsin hydrolysis (another hallmark of allergens), it thus seems very unlikely that the protein would have sailed through the CODEX process.

All this would probably be a scientific sidenote if it weren't for the fact that a senior Western Australian official took it upon himself to use the pea study as pretext to go on the offensive against genetically modified (GM) food. No sooner had CSIRO released its results than Minister of Agriculture Kim Chance announced the setting up of an "independent study" to review the possibility that "when a gene is taken out of one organism and put into another, the protein expressed in that gene may be different." The study was needed, Chance said, to investigate the propensity of rats fed $B t$ transgenic corn to develop "cancerous and pre-cancerous growths" and the potential of "GM DNA to enter animal bodies." A few days later, the Western Australian newspaper reported that Chance had awarded the funding for the study to the Institute for Health and Environmental Research in Adelaide (http://www.iher.org.au/). This institute consists of three people with no scientific expertise in long-term feeding studies and a clear agenda against anything remotely connected to a transgene. So much for an independent study.

Chance is entitled to his opinion. But the day must come when he, and politicians like him, realize that absolute proof for the safety of GM (or any other) food is a scientific impossibility. We have in place a reliable assessment process to flag potentially allergenic recombinant proteins on a case-by-case basis. And with so many other priorities competing for taxpayer money, one must question whether the best interests of the Western Australian public have really been served. 